\title{
06.5
}

\section{Особенности фононного крыла люминесценции алмаза}

\author{
() С.И. Зиенко ${ }^{1}$, Д.С. Слабковский ${ }^{2}$ \\ ${ }^{1}$ Филиал Национального исследовательского университета „МЭИ“ в г. Смоленске, \\ Смоленск, Россия \\ ${ }^{2}$ Смоленский геммологический центр, Смоленск, Россия \\ E-mail: stanislav-zienko@rambler.ru
}

Поступило в Редакцию 28 февраля 2019г.

В окончательной редакции 7 марта 2019г.

Принято к публикации 7 марта 2019г.

\begin{abstract}
Экспериментально установлено, что спектр люминесценции алмаза при комнатной температуре содержит один или два пика в форме кривых Гаусса. Такой результат связан с экситон-фононным взаимодействием в алмазе, которое наряду с нуль-фононной линией содержит фононные повторения первого и второго порядка. Это явление характерно только для природных алмазов и отсутствует у синтетических образцов. Поэтому оно может найти применение для идентификации ограненных алмазов (бриллиантов).
\end{abstract}

Ключевые слова: природные и синтетические алмазы, экситон-фононное взаимодействие, параметр Хуанга-Риса, идентификация бриллиантов.

DOI: 10.21883/PJTF.2019.11.47815.17761a

Процесс формирования природного алмаза протекает в течение миллиона-миллиардов лет. Здесь процедура алмазообразования полностью завершена. У синтетических алмазов указанный процесс протекает в течение десятков-сотен часов и процедура алмазообразования далека от завершения. Следовательно, структура решетки природного алмаза отличается от структуры решетки алмаза лабораторного происхождения. Таким образом, для определения происхождения алмаза необходимо знать свойства его кристаллической решетки.

Для решения этой задачи в настоящей работе предлагается использовать фононное крыло спектра люминесценции алмаза при комнатной температуре. Данный вопрос в литературе практически не рассматривался. Между тем его решение представляет большой научный и практический интерес. В последнем случае решается проблема определения происхождения бриллиантов. Для возбуждения люминесценции алмаза использовался лазер с длиной волны $532 \mathrm{~nm}$. Спектры люминесценции регистрировались с помощью спектрометра-флуориметра РАOC-4 [1]. Измерения выполнялись при комнатной температуре в диапазоне $\lambda=530-800 \mathrm{~nm}$. Анализ данных проводился по шкале энергии: $E=1240 / \lambda$, где $\lambda$ измеряется в $\mathrm{nm}, E-$ в $\mathrm{eV}$ и шкале частот. В последнем случае из шкалы энергии вычиталась постоянная составляющая $E_{0}=1.55 \mathrm{eV}$ $\left(E_{0}=1240 / 800\right)$. Частота локальных колебаний находится как $v_{\text {local }}=\left(h v-E_{0}\right) / h$, где $h-$ постоянная Планка. Для упрощения анализа принимали $h=1$ и полагали $v_{\text {local }}=f$, где $f-$ условная частота, измеряемая в $\mathrm{Hz}[2]$.

Экспериментальные спектры проходили процедуру математической обработки сигнала. Для этого использовалась фурье-фильтрация. В результате узко- и широкополосные линии люминесценции, присутствующие на спектральной кривой, полностью исчезают. Спектр люминесценции состоит из фононного крыла и несет информацию об общем состоянии решетки алмаза. В работе представлены результаты исследования 38 образцов ограненных алмазов (бриллиантов) природного происхождения. Были исследованы следующие образцы: I Кр-57, фантазийный коричневый/9, 0.54 кар (9 группа чистоты, масса 0.54 карат); Е - Кр-57, фантазийный глубокий желто-оранжеватый/8, 0.71 кар; Н - Ов57, фантазийный темный оранжевато-коричневый/9, 0.39 кар [1].

Обнаружено существование трех характерных типов фононных крыльев. Они отличаются друг от друга

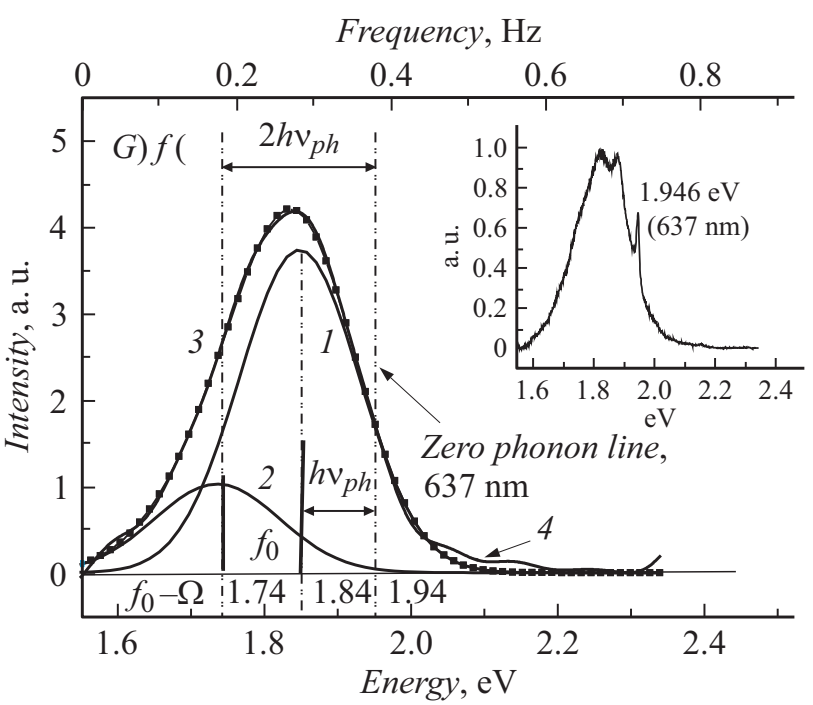

Рис. 1. Дифференциальная функция распределения фононного крыла $G(f)$ спектра люминесценции алмаза (образец I) (3) и его элементарные составляющие ( 1 и 2$)$ в форме кривых Гаycca. 
Численные значения параметров элементарных составляющих спектров

\begin{tabular}{|c|c|c|c|c|c|c|c|c|c|}
\hline Образец & $\begin{array}{c}\text { Номер } \\
\text { пика }\end{array}$ & $\begin{array}{c}\text { Площадь } \\
\text { C }\end{array}$ & $\begin{array}{l}f_{0}, \\
\mathrm{~Hz}\end{array}$ & $\begin{array}{l}\Delta f \\
\mathrm{~Hz}\end{array}$ & $H$ & $\begin{array}{c}\Delta P_{s}, \\
\mathrm{eV}\end{array}$ & $S_{\mathrm{HR}}$ & $m$ & $\begin{array}{l}\Omega, \\
\mathrm{Hz}\end{array}$ \\
\hline I & $\begin{array}{l}1 \\
2\end{array}$ & $\begin{array}{l}0.76 \\
0.23\end{array}$ & $\begin{array}{l}0.298 \\
0.185\end{array}$ & $\begin{array}{l}0.171 \\
0.163\end{array}$ & $\begin{array}{l}3.7 \\
1.0\end{array}$ & 1.47 & 14.7 & 0.58 & 0.1 \\
\hline E & $\begin{array}{l}1 \\
2\end{array}$ & $\begin{array}{l}0.91 \\
0.09\end{array}$ & $\begin{array}{l}0.307 \\
0.556\end{array}$ & $\begin{array}{l}0.254 \\
0.160\end{array}$ & $\begin{array}{l}3.4 \\
0.5\end{array}$ & 1.1 & 11.0 & 0.2 & 0.1 \\
\hline $\mathrm{H}$ & 1 & 1.02 & 0.54 & 0.240 & 4.1 & 1.33 & 9.5 & 0 & 0.14 \\
\hline
\end{tabular}

формой и расположением их максимумов относительно нуль-фононной линии (zero phonon line). Фононные спектры (рис. 1,2$)$ имеют сложную форму и разлагаются на две либо одну элементарные составляющие в форме кривой Гаусса. Для разложения использовалась программа Origin. На вставке к рис. 1 показан спектр, полученный в результате измерений без фильтрации. На нем можно видеть характерный выброс. Ему соответствует так называемый отрицательно заряженный $(\mathrm{N}-V)^{-}$-центр с максимумом нуль-фононной линии $637 \mathrm{~nm}(1.946 \mathrm{eV})$ [3]. Этот центр хорошо проявляется в бриллиантах с фантазийной окраской.

Пик 1 (рис. 1) соответствует полосе первого фононного повторения, пик 2 - полосе второго фононного повторения экситонной люминесценции алмаза [4]. Их максимумы сдвинуты по шкале энергии относительно нуль-фононной линии на величину $h v_{p h}$ и $2 h v_{p h}$ соответственно.

Судя по величине энергии $\left(h v_{p h}=0.1 \mathrm{eV}\right)$, фононы проявляют свойства оптических фононов. Характерной особенностью данного фононного спектра является то, что частота пика 2 меньше частоты основного пика 1. Следовательно, здесь проявляются свойства стоксовой люминесценции. Подобными признаками обладают бриллианты с ординарной окраской (бесцветные или с небольшим оттенком) (18 образцов) и два образца с фантазийной окраской.

В другом случае (рис. 2) частота пика 2 больше частоты пика 1. В данном случае имеет место антистоксовая люминесценция.

Здесь фононные свойства проявляет только пик 1 . Энергия фонона здесь, так же как и в предыдущем случае, составляет $0.1 \mathrm{eV}$. Характерной особенностью пика 2 является его небольшая величина относительно общей энергии фононного крыла: для 12 образцов из 18 бриллиантов с фантазийной окраской она составляла от 2 до $6 \%$, для двух - 20\%, для одного - 9\% (рис. 2), в трех образцах пик 2 отсутствовал. В случае стоксовой люминесценции отношение энергии боковой полосы к полной энергии составляет 20-25\%.

Последний случай характерной формы фононного крыла следует из рис. 2, если в нем устранить пик 2. В этом случае спектр описывается симметричной кри-

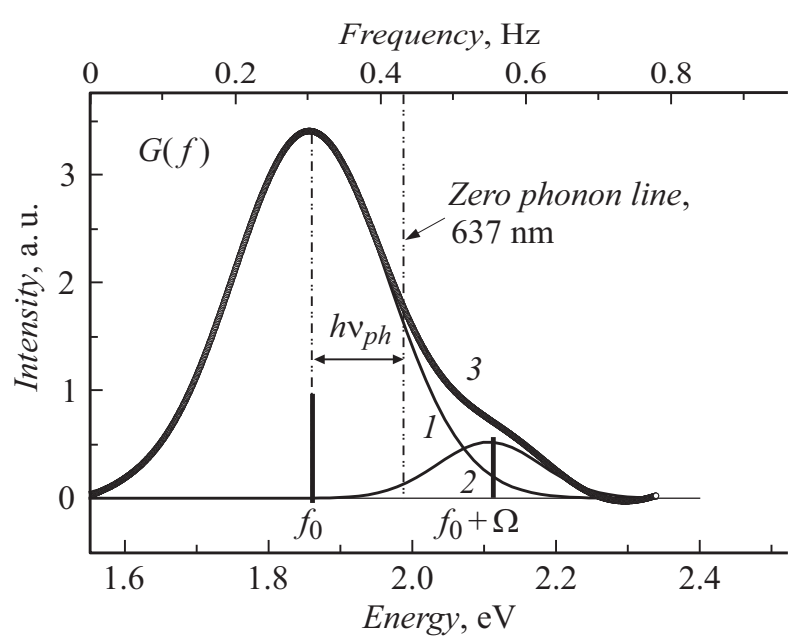

Рис. 2. Дифференциальная функция распределения фононного крыла $G(f)$ спектра люминесценции алмаза (образец Е) (3) и его элементарные составляющие (1 и 2) в форме кривых Гаyсcа.

вой Гаусса, подобной кривой 1 (рис. 2). Здесь энергия фонона $h v_{p h}=0.14 \mathrm{eV}($ образец $\mathrm{H})$.

В первом приближении спектры, изображенные на рис. 1 и 2, можно представить в форме узкополосного амплитудно-модулированного колебания (жирные отрезки прямых линий). Амплитуды этих отрезков равны площадям, ограниченным соответствующими кривыми Гаусса. Обозначим площади пиков 1 и 2 как $C_{1}$ и $C_{2}$ соответственно. В этом случае $C_{2}=m C_{1} / 2$, где $m-$ глубина модуляции. Модулированное колебание можно трактовать как колебание с несущей частотой $f_{0}$, но его амплитуда уже не постоянная величина, а изменяется во времени по закону управляющего воздействия с низкой частотой $\Omega$ и глубиной модуляции $m$. Низкую частоту может иметь только решетка алмаза $\left(\Omega=v_{\text {local }}\right)$. Следовательно, происхождение боковых полос спектров люминесценции обусловлено инерционными свойствами решетки, тогда как основная полоса связана с конечным временем перехода оптического электрона с возбужденного уровня в установившееся состояние. 
Физически отсутствие боковой полосы соответствует ситуации, когда экситон испускает фононы без изменения равновесия колеблющихся атомов решетки [4].

Для количественного анализа спектров можно получить уравнение импульсной (временно́й) характеристики в следующем виде [2]:

$$
g(t)=\left\{A_{1}^{2}(t)+A_{2}^{2}(t)+2 A_{1}(t) A_{2}(t) \cos 2 \pi \Omega t\right\}^{1 / 2} .
$$

Здесь $\quad A_{1}(t)=C_{1} \exp \left(-a_{1} t^{2}\right), \quad A_{2}(t)=C_{2} \exp \left(-a_{2} t^{2}\right)$, $a_{1}=3.5 \Delta f_{1}^{2}, a_{2}=3.5 \Delta f_{2}^{2}$, где $\Delta f_{1}$ и $\Delta f_{2}$ - ширина полос на их полувысоте. Уравнение (1) полезно использовать для проверки точности разложения фононных спектров на элементарные составляющие [2]. Для этого с помощью обратного фурье-преобразования фононного крыла численным методом находят импульсную характеристику $g^{*}(t)$, которую сравнивают c $g(t)$, полученной аналитическим методом по формуле (1). Параметры спектров представлены в таблице. Для оценки степени экситон-фононного взаимодействия используют параметр Хуанга-Риса: $S_{\mathrm{HR}}=\Delta P_{s} / h v_{p h}$. Здесь $\Delta P_{s}$ - потери энергии на этапе люминесцентного излучения.

Потери энергии находились с помощью равенства Парсеваля

$$
\Delta P_{s}=\int_{0}^{\infty} g^{2}(t) \mathrm{d} t .
$$

Параметры $\Delta P_{s}$ и $S_{\mathrm{HR}}$ представлены в таблице. Параметр Хуанга-Риса имеет большие значения (9.5-14.7), что свидетельствует о сильной электрон-фононной связи в алмазе. Для образца Е с антистоксовой люминесценцией параметр $S_{\mathrm{HR}}$ получен при условии, что энергия пика 1 намного больше энергии пика 2 (рис. 2). Подобные значения $S_{\mathrm{HR}}$ имели и другие исследованные образцы бриллиантов. Полученные результаты согласуются с данными, представленными в работе [5] для крупных алмазов.

В синтетических алмазах спектр люминесценции содержит от трех до семи пиков. Их свойства заметно отличаются от свойств природных алмазов [2]. Рассмотренное явление может быть использовано как один из методов определения происхождения бриллиантов.

\section{Конфликт интересов}

Авторы заявляют, что у них нет конфликта интересов.

\section{Список литературы}

[1] Зиенко С.И., Слабковский Д.С. // Вестн. МЭИ. 2015. № 5. C. $90-98$.

[2] Зиенко С.И. // Успехи прикл. физики. 2018. Т. 6. № 4. C. $297-306$.

[3] Природные алмазы России. Науч.-справоч. изд. / Под ред. В.Б. Кваскова. М.: Энергоатомиздат, 1990. 248 с

[4] Гросс Е.Ф., Пермогоров С.А., Разбирин Б.С. // УФН. 1971. T. 103. B. 3. C. $431-446$.
[5] Миков С.Н., Иго А.В., Горелик В.С. // ФТТ. 1999. Т. 41. В. 6. C. $1110-1112$. 